\title{
Study of obstetric and perinatal outcome of twin pregnancy
}

\author{
Chandni V. Mehta ${ }^{1 *}$, Babulal S. Patel ${ }^{1}$, Akshay C. Shah ${ }^{1}$, Shashwat K. Jani ${ }^{1}$, Dipal C. Shah ${ }^{1}$, \\ Vismay B. Patel' ${ }^{2}$, Adwait B. Patel ${ }^{3}$
}

\author{
${ }^{1}$ Department of Obstetrics and Gynecology, Smt N. H. L. Municipal Medical College, SVPIMSR, Ahmedabad, \\ Gujarat, India \\ ${ }^{2}$ Department of Obstetrics and Gynecology, GCS Medical College, Hospital and Research Centre, Ahmedabad, \\ Gujarat, India \\ ${ }^{3}$ Department of Obstetrics and Gynecology, Smt N. H. L. Municipal Medical College, Sheth V. S. and C. M. Hospital, \\ Ahmedabad, Gujarat, India
}

Received: 04 April 2020

Accepted: 29 April 2020

*Correspondence:

Dr. Chandni V. Mehta,

E-mail: chandni.mehta19@gmail.com

Copyright: (C) the author(s), publisher and licensee Medip Academy. This is an open-access article distributed under the terms of the Creative Commons Attribution Non-Commercial License, which permits unrestricted non-commercial use, distribution, and reproduction in any medium, provided the original work is properly cited.

\begin{abstract}
Background: Multifetal pregnancy constitutes a significant portion of high-risk pregnancies. This is due to the increasing obstetric and perinatal morbidity and mortality rates associated with it. Maternal and perinatal outcome of twin pregnancies has been evaluated in this study.

Methods: Total 30 patients with twin pregnancy and having gestational age more than 28 weeks were included in this observational study.

Results: Incidence of twins in the study was found to be $2 \%$. Twin pregnancies were more common in multiparous women aged between 20 and 30 years. Most common foetal presentation was vertex- vertex presentation. Most common maternal complication was preterm labour seen in $67 \%$ women, followed by anaemia seen in $50 \%$ women. Most of the women were delivered by caesarean section (63.3\%). Most common perinatal complication was birth hypoxia (41.6\%). Other perinatal complications were jaundice, septicemia, intrauterine growth restriction. $71 \%$ of the neonates had birth weight less than $2.5 \mathrm{~kg}$. Perinatal mortality was found to be $11.6 \%$.

Conclusions: Twin pregnancies are high risk pregnancies associated with higher obstetric and perinatal morbidity. Perinatal morbidity was more common for the second coming twin. Regular antenatal visits, planned delivery and better NICU facilities can help combat these complications. A team of skilled obstetricians and pediatricians along with a multidisciplinary approach is essential for the effective management of twin pregnancies.
\end{abstract}

Keywords: Maternal and perinatal morbidity, Preterm labour, Twin pregnancy

\section{INTRODUCTION}

Multiple pregnancy constitutes a significant portion of high-risk pregnancies. Maternal adaptation to twin pregnancy leads to various complications. It is of importance to obstetricians and paediatricians due to its significant maternal and perinatal risk. Twin pregnancies are associated with complications like antepartum haemorrhage, post-partum haemorrhage, preeclampsia, eclampsia, polyhydramnios, anaemia, increased incidence of caesarean sections and preterm deliveries in comparison with singleton pregnancies. ${ }^{1-4}$ Multiple pregnancies are also associated with complications like acardiac twins, conjoint twins and twin-twin transfusion syndrome. Such complications are exclusive to twin pregnancy. Prematurity, low birth weight, IUGR, sepsis, jaundice and respiratory distress are some of the perinatal complications seen in twins. Due to better NICU facilities and trained personnel, perinatal outcome of twins has improved. The incidence of multiple pregnancies in the 
world is 2-20 per 1000 births. ${ }^{5}$ Due to the increasing use of assisted reproductive techniques, decline in fertility and increasing number of women becoming pregnant at an advanced age, the incidence of multiple pregnancies is increasing dramatically. This study consists of evaluation of feto-maternal outcome in twin pregnancies.

\section{METHODS}

The type of study is prospective observational study. It was carried out in the department of obstetrics and gynecology, SVPIMSR, Ahmedabad, Gujarat, India from July 2019 to December 2019 (6 months).

Out of 1500 patients delivered in the hospital during this time period, 30 were twin pregnancies. They were received either from the emergency department, outpatient department or referred from other hospitals.

A total 30 patients were selected for the study after applying the criteria.

\section{Inclusion criteria}

- Women with twin pregnancy, gestational age more than 28 weeks.

\section{Exclusion criteria}

- Singleton pregnancy, triplets and higher order pregnancies, gestational age less than 28 weeks.

The diagnosis of twin pregnancy was established by transabdominal ultrasonographic imaging. Detailed history of patients including age, parity, menstrual history, obstetric history, family history of multiple pregnancy and gestational age was noted. Patients were also asked about the use of assisted reproductive techniques. Causative factors for twin pregnancy were noted. Maternal complications such as preeclampsia, preterm labour, anaemia, urinary tract infection, antepartum and postpartum haemorrhage were studied. Patients were monitored throughout labour. Outcome of each twin pregnancy was studied in which the number of twins delivered spontaneously vaginally, those requiring instrumental delivery, assisted breech deliveries or caesarean section was noted. Perinatal complications such as prematurity, low birth weight, jaundice, sepsis, birth hypoxia was studied. Apgar scores and twins requiring NICU admissions were noted.

All the data was entered in excel sheets and relevant tables and charts were prepared.

\section{RESULTS}

Out of the total 1500 patients delivered in study hospital from July 2019 to December 2019, 30 women had twin pregnancy. The incidence of twins in the study was $2 \%$.
A total $55 \%$ patients were un-booked, $20 \%$ patients were referred from peripheral hospitals and $25 \%$ were booked (Figure 1).

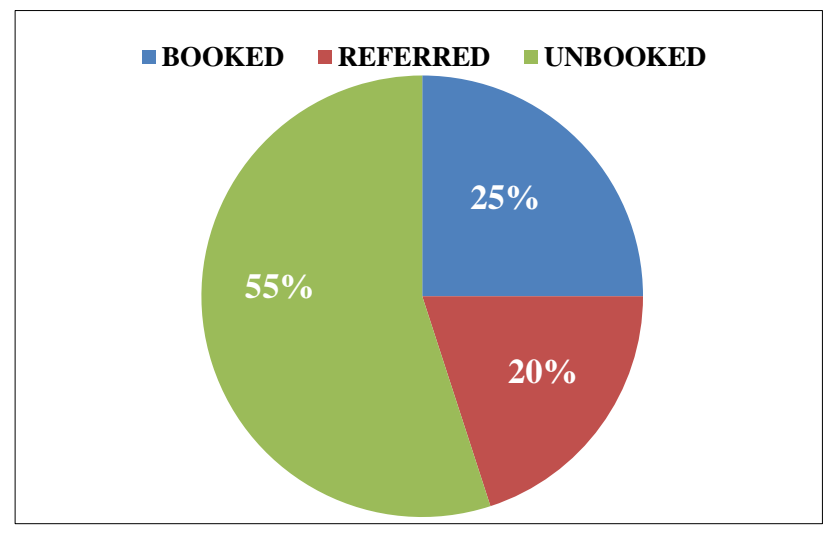

Figure 1: Incidence of multiple pregnancy according to booking status.

Table 1: Demographic and obstetric profile of the patients $(n=30)$.

\begin{tabular}{|lll|}
\hline Parameter & Number $(\mathbf{N}=30)$ & Percentage \\
\hline Age & & \\
\hline$<20$ years & 2 & $6.6 \%$ \\
\hline 20-30 years & 18 & $60 \%$ \\
\hline$>30$ years & 10 & $33.3 \%$ \\
\hline Parity & & \\
\hline primipara & 6 & $20 \%$ \\
\hline multipara & 24 & $80 \%$ \\
\hline
\end{tabular}

A total $60 \%$ patients were aged between 20 and 30 years. $80 \%$ were multipara and $20 \%$ were primipara (Table 1 ).

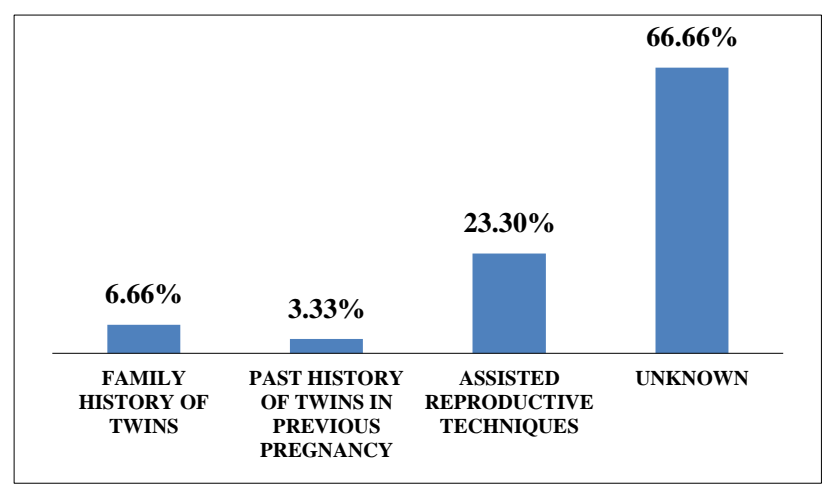

Figure 2: Causes of twin pregnancy.

The use of assisted reproductive techniques was found to be a cause of twins in $23.3 \%$ women. Family history of twins was seen in $6.66 \%$. Past history of twins in previous pregnancy was present in $3.33 \%$. No causative factor was found in $66.66 \%$ women (Figure 2).

On determination of chorionicity, $60 \%$ were diamniotic monochorionic, $26.6 \%$ were diamniotic dichorionic and 
$10 \%$ were monochorionic-monoamniotic. Chorionicity was not known in $3.3 \%$ cases (Figure 3 ).

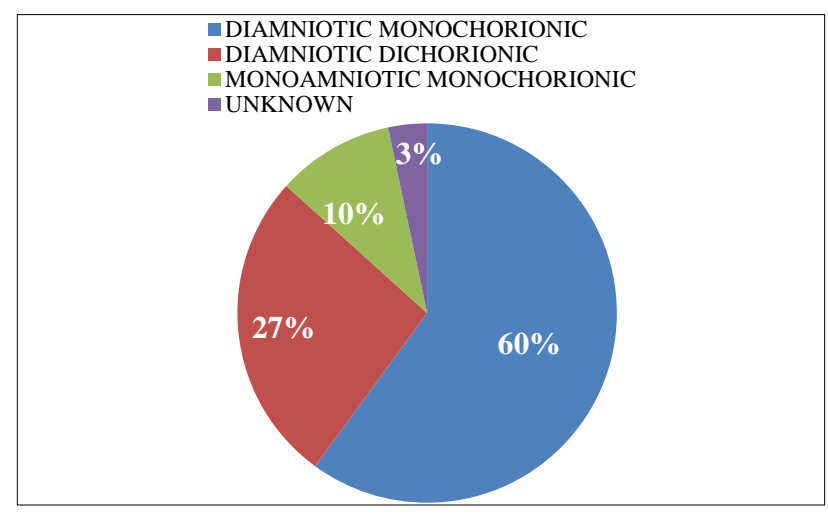

Figure 3: Distribution of patients according to chorionicity.

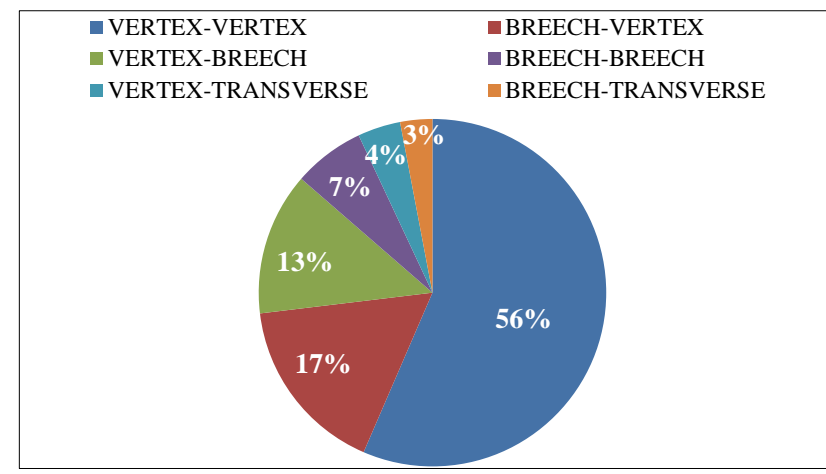

Figure 4: Distribution of twin pregnancies according to presentation.

Most common presentation in twins is vertex-vertex presentation (56.6\% patients). Second most common is Breech-vertex in $16.6 \%$ women (Figure 4).

Table 2: Obstetric profile of patients.

\begin{tabular}{|lll|}
\hline \multicolumn{2}{|l|}{ Gestational age at delivery } \\
\hline Parameter & Number & Percentage \\
\hline 28-30 weeks & 1 & $3.3 \%$ \\
\hline $30-34$ weeks & 16 & $53.3 \%$ \\
\hline $34-38$ weeks & 10 & $33.3 \%$ \\
\hline$>38$ weeks & 3 & $10 \%$ \\
\hline
\end{tabular}

Table 3: Distribution of patients according to the mode of delivery.

\begin{tabular}{|llll|}
\hline $\begin{array}{l}\text { Mode of } \\
\text { delivery }\end{array}$ & $\begin{array}{l}\mathbf{1}^{\text {st }} \text { twin } \\
(\%)\end{array}$ & $\begin{array}{l}2^{\text {nd }} \text { twin } \\
(\%)\end{array}$ & $\begin{array}{l}\text { Total number } \\
(\%)\end{array}$ \\
\hline Spontaneous & $8(26.6 \%)$ & $4(13.3 \%)$ & $12(20 \%)$ \\
\hline $\begin{array}{l}\text { Assisted } \\
\text { breech }\end{array}$ & $3(10 \%)$ & $4(13.3 \%)$ & $7(11.6 \%)$ \\
\hline Instrumental & $1(3.3 \%)$ & $2(6.6 \%)$ & $3(5 \%)$ \\
\hline LSCS & $18(60 \%)$ & $20(66 \%)$ & $38(63.3 \%)$ \\
\hline Total & $30(100)$ & $30(100)$ & $60(100)$ \\
\hline
\end{tabular}

A total 53\% patients delivered between 30- and 34-weeks gestational age. $33 \%$ patients delivered between 34 and 38 weeks, $10 \%$ beyond 38 weeks and $3 \%$ between 28 and 30 weeks (Table 2). A total 4 patients delivered the first and second twin spontaneously. Another 4 patients delivered the first twin spontaneously, but for the second twin, one was delivered by assisted breech method, one by forceps and two by caesarean section. Both the twins were delivered by assisted breech delivery in 3 patients and by instrumental delivery in 1 patient (Table 3 ).

Mode of delivery in $63.3 \%$ women was by caesarean section. Out of 30 women, 18 underwent caesarean section for the first twin itself. Two women, who delivered the first twin spontaneously vaginally, were taken for caesarean section for the second twin due to transverse lie and fetal distress respectively. In $83.3 \%$ twins, interval of deliveries between first and second twin was $<15$ min (Table 4).

Table 4: Interval of delivery between the two twins and indication of caesarean section.

\begin{tabular}{|c|c|c|}
\hline \multicolumn{3}{|c|}{$\begin{array}{l}\text { Interval of delivery between the first and second } \\
\text { twin }\end{array}$} \\
\hline Interval & Number & Percentage \\
\hline$<15 \min$ & 25 & $83.3 \%$ \\
\hline $15-30 \mathrm{~min}$ & 4 & $13.3 \%$ \\
\hline $31-60 \mathrm{~min}$ & 1 & $3.3 \%$ \\
\hline \multicolumn{3}{|c|}{ Indication of LSCS in twins $(n=20)$} \\
\hline Malpresentation & 11 & $55 \%$ \\
\hline Previous CS & 3 & $15 \%$ \\
\hline Fetal distress & 3 & $15 \%$ \\
\hline $\mathrm{PIH}$ & 1 & $5 \%$ \\
\hline Non progress of labour & 1 & $5 \%$ \\
\hline Antepartum haemorrhage & 1 & $5 \%$ \\
\hline
\end{tabular}

Table 5: Complications found in antenatal patients $(\mathbf{n}=\mathbf{3 0})$.

\begin{tabular}{|lll|}
\hline Complication & Number & Percentage \\
\hline Anaemia & 15 & $50 \%$ \\
\hline Hyperemesis gravidarum & 2 & $6.6 \%$ \\
\hline $\begin{array}{l}\text { Hypertension } \\
\text { (PIH/preeclampsia) }\end{array}$ & 12 & $40 \%$ \\
\hline Polyhydramnios & 2 & $6.6 \%$ \\
\hline $\begin{array}{l}\text { APH (abruption, placenta } \\
\text { previa) }\end{array}$ & 1 & $3.3 \%$ \\
\hline PROM & 10 & $33.3 \%$ \\
\hline UTI & 5 & $16.6 \%$ \\
\hline Gestational diabetes & 2 & $6.6 \%$ \\
\hline No associated complications & 5 & $16.6 \%$ \\
\hline Complications inherent to twinning & 1 & $3.3 \%$ \\
\hline TTTS & 1 & $3.3 \%$ \\
\hline $\begin{array}{l}\text { SIUFD (single intrauterine } \\
\text { fetal demise) }\end{array}$ & 1 & $100 \%$ \\
\hline
\end{tabular}

(Note: total percentage will not be equal to $100 \%$ as some patients had more than one complication). 
Most common maternal complication found in twin pregnancy was preterm labour seen in $67 \%$ patients. Other complications were anaemia $(50 \%)$, PIH $(40 \%)$, premature rupture of membranes $(33 \%)$ and post-partum haemorrhage $(16.6 \%)$.

Table 6: Distribution of intrapartum complications associated with twin pregnancies $(n=30)$.

\begin{tabular}{|lll|}
\hline Complication & Number & Percentage \\
\hline Preterm labour & 20 & $67 \%$ \\
\hline PPH & 5 & $16.6 \%$ \\
\hline Sepsis & 1 & $3 \%$ \\
\hline Preterm LSCS & 8 & $27 \%$ \\
\hline Post-partum eclampsia & 1 & $3.3 \%$ \\
\hline No complication & 8 & $27 \%$ \\
\hline
\end{tabular}

(Note: total percentage will not be equal to $100 \%$ as some patients had more than one complication).

One patient with monochorionic twins was associated with twin-twin transfusion syndrome (TTTS) and one patient with dichorionic twin pregnancy was associated with single intrauterine fetal demise (SIUFD) in first trimester and delivered in $3^{\text {rd }}$ trimester in which one of the fetus was healthy and the other fetus was dead with weight 250 grams (Table 5 and 6). Patients who presented with preterm labour pain were managed conservatively. Antibiotics, tocolytic drugs (nifedipine, progesterone), magnesium sulfate as well as glucocorticoids were administered. They help in prevention of preterm labour as well as help in improving the neonatal outcome by reducing RDS (respiratory distress syndrome), IVH (intraventricular haemorrhage), and NEC (necrotising enterocolitis). Magnesium sulfate acts as a neuroprotective agent.

Respiratory distress and birth hypoxia constitute a major part of perinatal morbidity $(41.6 \%)$. IUGR constitutes $16.6 \%$, jaundice constitutes $16.6 \%$ whereas neonatal sepsis constitutes $8 \%$ of perinatal complications (Table 7).

Table 7: Causes of perinatal morbidity $(n=60)$.

\begin{tabular}{|lll|}
\hline Morbid condition & Number & Percentage \\
\hline Prematurity & 50 & $83.3 \%$ \\
\hline Birth weight & & \\
\hline$<1 \mathrm{~kg}$ & 5 & $8.3 \%$ \\
\hline $1-1.5 \mathrm{~kg}$ & 20 & $33.3 \%$ \\
\hline $1.6-2.5 \mathrm{~kg}$ & 18 & $30 \%$ \\
\hline$>2.5 \mathrm{~kg}$ & 17 & $28.3 \%$ \\
\hline IUGR & 10 & $16.6 \%$ \\
\hline Birth asphyxia /hypoxia/RDS & 25 & $41.6 \%$ \\
\hline Septicaemia & 5 & $8.3 \%$ \\
\hline Jaundice & 10 & $16.6 \%$ \\
\hline Anaemia & 10 & $16.6 \%$ \\
\hline Congenital malformations & 2 & $3.3 \%$ \\
\hline
\end{tabular}

Table 8: Comparison of birth weights between first and second twins.

\begin{tabular}{|lll|}
\hline Parameter & Twin 1 & Twin 2 \\
\hline \multirow{2}{*}{ Mean birth weight (grams) } & $\begin{array}{l}1900 \\
\text { grams }\end{array}$ & $\begin{array}{l}1560 \\
\text { grams }\end{array}$ \\
\hline
\end{tabular}

Table 9: Comparison of incidence of birth hypoxia amongst first twin and second twin.

\begin{tabular}{|lllllll|}
\hline Birth hypoxia & Twin 1 (T1) & $\begin{array}{l}\text { Twin (T1) } \\
\text { Percentage }\end{array}$ & Twin 2 (T2) N & $\begin{array}{l}\text { Twin 2 (T2) } \\
\text { Percentage }\end{array}$ & Total N (T1+T2) & Percentage \\
\hline Present & 10 & $33.3 \%$ & 22 & $73.3 \%$ & 32 & $53.3 \%$ \\
\hline Absent & 20 & $66.6 \%$ & 8 & $26.6 \%$ & 28 & $46.6 \%$ \\
\hline Total & 30 & $100 \%$ & 30 & $100 \%$ & 60 & $100 \%$ \\
\hline
\end{tabular}

Table 10: Comparison of Apgar scores between the first and second coming twins.

\begin{tabular}{|lllllll|}
\hline Apgar scores & Twin 1 (T1) & Twin 1 (T1) & Twin 2 (T2) & Twin 2 (T2) & Total N (T1+T2) & Percentage \\
\hline$<7$ at 1 min & 12 & $40 \%$ & 16 & $53.3 \%$ & 28 & $46.6 \%$ \\
\hline$>7$ at 1 min & 28 & $60 \%$ & 14 & $46.7 \%$ & 32 & $53.3 \%$ \\
\hline Total & 30 & $100 \%$ & 30 & $100 \%$ & 60 & $100 \%$ \\
\hline
\end{tabular}

Second of the coming twins were associated with more perinatal complications than the first twin. Birth weight less than $2.5 \mathrm{~kg}$ is defined as low birth weight (LBW). In this study, $71.7 \%$ of the new-borns were low birth weight. Birth weight of the second coming twins was found to be lower than the first coming twins. The mean birth weight of first coming twins (twin 1) was 1900 grams and that of second coming twin was 1560 grams (twin 2) (Table 8). The second coming twins had a higher incidence of birth hypoxia $(73.3 \%)$ as compared to the first twin (26.6\%) (Table 9).

A total $46 \%$ neonates had Apgar score less than 7 at 1 minute. Out of this, percentage of first and second coming twins having Apgar score of less than 7 at 1 minute was $40 \%$ and $53.3 \%$ respectively (Table 10 ). 
A total $55 \%$ of total neonates were admitted in NICU (twin 1: $43.3 \%$ and twin 2: 66.6\%). Out of 60 twins delivered, 59 were live births.

There was 1 macerated IUD baby weighing 250 grams. Due to perinatal complications, 6 babies died in the first week. Perinatal mortality in this study was $11.6 \%$. Out of the 2 babies delivered instrumentally, 1 died. Hence highest mortality was associated with instrumental delivery $(50 \%)$ (Table 12$)$. Neonatal outcome is summarized (Table 13). As gestational age increases, perinatal morbidity and mortality decreases.

Table 11: Comparison of NICU requirement in first twin and second coming twin.

\begin{tabular}{|lllllll|}
\hline $\begin{array}{l}\text { NICU } \\
\text { requirement }\end{array}$ & Twin 1 N & Twin 1\% & Twin 2 N & Twin 2 \% & Total N (T1+T2) & Percentage \\
\hline Required & 13 & $43.3 \%$ & 20 & $66.6 \%$ & 33 & $55 \%$ \\
\hline Not required & 17 & $56.6 \%$ & 10 & $33.3 \%$ & 27 & $45 \%$ \\
\hline Total & 30 & $100 \%$ & 30 & $100 \%$ & 60 & $100 \%$ \\
\hline
\end{tabular}

Table 12: Perinatal death in twin 1 and twin $2(\mathrm{~N}=60)$ in relation to the mode of delivery.

\begin{tabular}{|lllllll|}
\hline Mode of delivery & $\begin{array}{l}\mathbf{1}^{\text {st }} \\
\text { Twin }\end{array}$ & $\begin{array}{l}2^{\text {nd }} \\
\text { Twin }\end{array}$ & $\begin{array}{l}\text { Perinatal death } \\
\text { (Twin 1) }\end{array}$ & $\begin{array}{l}\text { Perinatal death } \\
\text { (Twin 2) }\end{array}$ & $\begin{array}{l}\text { Total perinatal } \\
\text { death }\end{array}$ & $\begin{array}{l}\text { Perinatal } \\
\text { mortality \% }\end{array}$ \\
\hline Spontaneous & 8 & 4 & 1 & 3 & 4 & $57.14 \%$ \\
\hline Assisted breech & 3 & 4 & 0 & 1 & 1 & $14.28 \%$ \\
\hline Instrumental & 1 & 2 & 0 & 1 & 1 & $14.28 \%$ \\
\hline LSCS & 18 & 20 & 0 & 1 & 1 & $14.28 \%$ \\
\hline Total & 30 & 30 & 1 & 6 & 7 & $100 \%$ \\
\hline
\end{tabular}

Table 13: Neonatal outcome $(n=60)$.

\begin{tabular}{|lll|}
\hline Parameter & Number & Percentage \\
\hline Live births & 59 & $98.3 \%$ \\
\hline NICU admission & 33 & $55 \%$ \\
\hline Neonatal death at $1^{\text {st }}$ week & 6 & $10 \%$ \\
\hline $\begin{array}{l}\text { Single intrauterine fetal } \\
\text { demise }\end{array}$ & 1 & $1.6 \%$ \\
\hline Fresh still born & 0 & $0 \%$ \\
\hline Macerated still born & 0 & $0 \%$ \\
\hline
\end{tabular}

\section{DISCUSSION}

Twin pregnancies require multidisciplinary approach towards their management as twin pregnancies are high risk pregnancies. The incidence of twin pregnancy in this study was $2 \%$ which is similar to the traditional incidence of $0.2-2 \% .^{5}$ Owing to the increasing trend towards late child bearing and widespread use of assisted reproduction techniques, there is a higher incidence of twin pregnancies. $23.3 \%$ patients became pregnant after receiving treatment with ovulation induction drugs and IVF. Therefore $23.3 \%$ pregnancies were the result of iatrogenic twinning in contrast to the study by Sultana et al where the rate of iatrogenic twinning was $14 \% .^{6} 60 \%$ women were aged between 20-29 years. This finding is similar to a study by Spellacy et al where $55 \%$ were aged between $20-29$ years. $^{7} 80 \%$ women were multipara which is consistent to a report by Spellacy et al where $84.2 \%$ women were multipara. Most common indication of caesarean section was malpresentation found in 55\% which is comparable to Erdemoglu et al (46.3\%). ${ }^{8}$ Most common presentation at birth was vertex-vertex $(56.6 \%)$ which was found to be similar with another study by Chowdhury et al (47.5\%) and Panwala et al (51.4\%). ${ }^{9,10}$

Most common method of delivery in this study was by lower segment cesarean section $(63.3 \%)$, consistent to studies by Chowdhury and Sultana $(49.1 \%$ and $56 \%$ respectively). ${ }^{6,10} 20 \%$ of the total twins delivered vaginally spontaneously, $11.6 \%$ twins underwent assisted breech delivery and 5\% twins underwent instrumental delivery. The delivery interval between first and second twin was $<15 \mathrm{~min}$ in $83.3 \%$ women and $<30 \mathrm{~min}$ in $13.3 \%$ women. In one patient delivery interval between first and second twin was 50 minutes. Higher neonatal morbidity was found in the second coming twins when the delivery interval was $>15 \mathrm{~min}$. To reduce perinatal risk, the delay between the two deliveries should be minimized. Most common maternal complication in twin pregnancy was found to be preterm labour (67\%). A higher pre term caesarean section rate of $27 \%$ was found. This is in contrast to previous studies by Papicrnik, Chowdhury and Sultana where preterm delivery rates were $50.7 \%, 41.5 \%$ and $44 \%$ respectively. ${ }^{6,10,11}$

Due to increased association with medical complications, there was a higher rate of earlier caesarean deliveries. Second most common complication in this study seen in $50 \%$ women was anaemia which was higher than the corresponding figures reported by Chowdhury and Brown 
et al were $35.8 \%$ and $35.5 \% .^{10,12}$ However, a much higher incidence of anaemia was reported by Bangal et al $(84 \%) .{ }^{13}$ This variation could be due to difference in the prevalence of anaemia in different regions. Respiratory distress was observed in $41.6 \%$ of neonates. $73 \%$ of the second coming twin suffered from respiratory distress while $33 \%$ of first twins had distress. Hypertensive disorders were reported in $40 \%$ women in the present study. This is higher when compared to that observed in studies by Bangal et al and by Chowdhury et al where they were seen in $18 \%$ and $22.6 \%$ cases respectively. ${ }^{10,13}$

PPH complicated $16.6 \%$ cases in present study which was similar to the study by Chowdhury (18.9\%). ${ }^{10} 33.3 \%$ of the patients were had premature rupture of membranes (PROM). But Chowdhury and Sultana reported lower rate of PROM for twin pregnancy $(3.8 \%$ and $10 \%$ respectively). ${ }^{6,10}$ Twin-twin transfusion syndrome was seen in one patient where one twin had intrauterine growth restriction with oligohydramnios and the other twin had polyhydramnios. There was no maternal mortality in this study.

Perinatal mortality of $11.6 \%$ was found in this study which was higher than that found by Chowdhury and Sultana et al. ${ }^{6,10}$ Higher perinatal mortality was observed in unbooked patients $(55 \%)$ and patients referred from peripheral centres $(20 \%)$ in comparison to booked patients $(25 \%)$. This demonstrates the importance of regular and effective antental care for better outcome in the mother and baby. Still birth comprises of $1.6 \%$ of the total live births. About $55 \%$ of the neonates were admitted in NICU. Of these, 13 of the first coming twins and 20 of the second twins required NICU admission. $71 \%$ of twins were low birth weight $(<2.5 \mathrm{~kg})$ and $83.3 \%$ of neonates were preterm. $3.3 \%$ twins in this study were congenitally malformed. Second coming twin was worse affected in comparison to the first twin. The incidence of discordant growth in this study was $30 \%$. Apgar score of $<7$ at 1 min was observed in $56 \%$ of all babies. The incidence of $1 \mathrm{~min}$ Apgar score of $<7$ among twin 1 babies was $40 \%$ and among twin 2 babies was 53\%, showing that the second twin had lower Apgar score. Reasons for increased perinatal risk in twins are low birth weight and prematurity. It was found that earlier the gestational age at which delivery occurs, more are the chances of hypoxia, NICU admissions and deaths in neonates.

\section{CONCLUSION}

There is an increasing incidence of twins due to infertility treatment and advancing maternal age. Hence the associated maternal and fetal complications are higher.
Moreover, these complications are higher when twins are delivered at earlier gestational age. High-risk cases should be identified early and managed. Regular antenatal visits, adequate rest, administration of steroids, good nutrition are important to improve the outcome. Early hospitalisation, careful intrapartum monitoring and better NICU facilities are essential to reduce the risk to mother and baby.

\section{Funding: No funding sources Conflict of interest: None declared Ethical approval: Not required}

\section{REFERENCES}

1. Smits J, Monden C. Twinning across the developing world. PLoS One. 2011;6(9):e25239.

2. Sumathipala A, Siribaddana S, De Silva N, Fernando D, Abeysingha N, Dayaratne R, et al. Sri Lankan twin registry. Twin Res Human Genet. 2002;5(5):424-6.

3. Aisien AO, Olarewaju RS, Imade GE. Twins in Jos Nigeria: a seven-year retrospective study. Med Sci Monit. 2000;6:945-50.

4. Obiechina N, Okolie V, Eleje G. Twin versus singleton pregnancies: the incidence, pregnancy complications, and obstetric outcomes in a Nigerian tertiary hospital. Int J Womens Health. 2011;3:227.

5. Doris MC. Multiple pregnancy. Baillieres Clin Obstet Gynaecol. 1990;4:109-27.

6. Sultana H. Fetal and maternal outcome of twin pregnancy-a study of 50 cases. Bangladesh College of Physicians and Surgeons, Dhak; 1998.

7. Spellacy WN, Handler A, Ferre CD. A case control study of 1253 twin pregnancies from 1982-1987. Perinatal Data Base. 1990;75:198-71.

8. Erdemoglu M, Kale A, Akdeniz N, Yalinkaya A, Ozcan Y. Retrospective analysis of multiple pregnancies. Perinatal J. 2005;13(4):213-7.

9. Panwala NM, MondkarAM, Ranade VR, Purandare VN. Multiple pregnancy. A review of 116 cases. J Postgrad Med. 1972;18(3):108-14.

10. Chowdhury S. Clinical study on twin pregnancy, FCPS. Bangladesh College of Physicians and Surgeons, Dhaka, 1998.

11. Papiernik E, Keith L, Oleszczuk JJ, Cervantes A. What interventions are useful in reducing the rate of preterm delivery in twins? Clinical Obstet Gynecol. 1998;41(1):13-23.

12. Brown EJ, Dixon HG. Twin pregnancy. J Obstet Gynaecol Br Common. 1963;70:251.

13. Bangal VB, Patel SM, Khairnar DN. Study of maternal and foetal outcome in twin gestation at tertiary care teaching hospital. Int $\mathrm{J}$ Biomed Adv Res. 2012;3(10):758-62.

Cite this article as: Mehta CV, Patel BS, Shah AC, Jani SK, Shah DC, Patel VB, et al. Study of obstetric and perinatal outcome of twin pregnancy. Int $\mathbf{J}$ Reprod Contracept Obstet Gynecol 2020;9:2530-5. 